This document is the accepted manuscript version of the following article: Liao, Y., Dimopoulos Eggenschwiler, P., Rentsch, D., Curto, F., Boulouchos, K. (2017).

Characterization of the urea-water spray impingement in diesel selective catalytic

reduction systems. Applied Energy, 205, 964-975. http://doi.org/10.1016/

j.apenergy.2017.08.088

This manuscript version is made available under the CC-BY-NC-ND 4.0 1icense http:// creativecommons.org/1icenses/by-nc-nd/4.0/

\title{
Characterization of the urea-water spray impingement in diesel selective catalytic reduction systems
}

\section{Yujun Liao ${ }^{\mathrm{a}}$, Panayotis Dimopoulos Eggenschwiler ${ }^{\mathrm{a} \bowtie}$, Daniel Rentsch $^{\mathrm{b}}$, Francesco Curto $^{a}$, Konstantinos Boulouchos ${ }^{c}$}

a. Automotive Powertrain Technologies Laboratory, Empa, Swiss Federal Laboratories for Materials Science and Technology, $\mathrm{CH}-8600$ Dübendorf, Switzerland

b. Functional Polymers Laboratory, Empa, Swiss Federal Laboratories for Materials Science and Technology, CH-8600 Dübendorf, Switzerland

c. Aerothermochemistry and Combustion Systems Laboratory, ETH Zurich, CH-8092 Zürich, Switzerland

\begin{abstract}
Exhaust after-treatment selective catalytic reduction (SCR) systems based on urea-water solution are state-of-the-art technologies mitigating NOx emissions for diesel and lean combustion systems. Major challenges for implementing the systems are high NOx reduction performance, uniform mixture formation and solid deposits formation. This study presents a detailed analysis of the urea-water spray wall impingement and influences on reducing agent distribution and deposit formation, thus system performance. High speed images provide detailed information of the impingement process. Moreover, impinging spray mass flux distribution and droplet size distribution have been quantified under typical diesel exhaust flow conditions. The work has been performed with a commercial 3-Hole pressure-driven injector dosing into a flow channel.
\end{abstract}

Under all tested conditions, the impingement is significant. At gas flow conditions of $300^{\circ} \mathrm{C}, 200 \mathrm{~kg} / \mathrm{h}$, $35.6 \%$ of the injected fluid impinges on the opposed wall due to entrainment and evaporation. The entrainment level has been found to scale logarithmically with the gas flow momentum, related correlations are provided. Having an integrated analysis of a mechanical patternator and non-intrusive

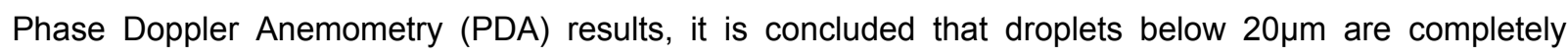
entrained or evaporated. The impingement rate is gradually increasing with increasing droplet diameter up

\footnotetext{
Corresponding author:

Panayotis Dimopoulos Eggenschwiler

Empa, Ueberlandstrasse 129, 8600 Duebendorf, Switzerland

Panayotis.Dimopoulos@empa.ch
} 
to $90 \mu \mathrm{m}$, while almost all larger droplets reach the opposed wall. High speed imaging shows in detail liquid film formation, film transport, liquid accumulation, nucleate boiling, urea crystallization and melting, as well as thin film evaporation prior to solid deposit formation. The spray impingement leads to liquid film formation. Relevant dimensions have been evaluated with digital image processing. Direct relationship of liquid accumulation to the solid deposit formation has been identified. The permanent solid deposit is consisting of cyanuric acid, biuret, ammelide and ammeline as identified by nuclear magnetic resonance spectroscopy.

\section{Key words: Selective Catalytic Reduction NOx, Urea Water Solution Spray Impingement, Solid Deposits Formation, Optical Diagnostics, Nuclear Magnetic Resonance spectroscopy}

\section{Introduction}

Diesel engines relying on lean combustion are widely used in the transportation sector due to their high energy conversion efficiency. Concerning heavy duty applications, freight transport and mobile machines, there are no potential alternatives to diesel engines in the next decades. However, they produce harmful pollutants, such as NOx and particles. NOx is one of the major and most harmful environmental pollutants induced by the transportation sector. They lead to the acid rain and formation of ground level ozone, which leads to health and environmental problems. Methods to reduce NOx emissions include in-cylinder techniques and exhaust after-treatment systems. In-cylinder techniques which aim to lower peak temperatures tend to decrease engine efficiency and increase soot formation. Therefore, exhaust selective catalytic reduction (SCR) systems are currently the promising technique to reduce NOx emissions without sacrificing engine efficiency [1]. SCR systems rely on injection of ammonia precursor in the exhaust gas. In real applications, 32.5\% urea-water solution (UWS, trademark AdBlue) is used as an ammonia precursor because of its non-toxicity and lowest freezing point. The UWS injection is followed by the evaporation of water from spray droplets. Thereafter, thermal decomposition of urea and hydrolysis of isocyanic acid take place [1-3], resulting in the production of ammonia. Ammonia reacts with NOx to water and nitrogen.

The main challenges for the implementation of mobile urea-SCR systems include homogeneous distribution of urea [4-6] as well as mitigation of solid deposit formation [7-9]. Because of compact design 
requirements of the exhaust pipe and relatively long time scales of urea thermal decomposition [10], the spray impingement on the exhaust pipe or on a mixer is unavoidable [2]. As the wall temperature drops below a certain threshold, liquid film starts forming [2]. Evaporation from the wall film leads to further cooling and increasing risk of deposit formation such as cyanuric acid, biuret, ammelide etc. $[3,11-13]$.

Numerical simulation efforts concerning SCR sprays [2,14-22] are more established in the literature. However, they deliberately point out that there is a lack of experimental data in this field. Only recently a limited number of experimental data on SCR sprays has been available [10,23-28]. SCR pressure-driven injectors operated at low pressures don't allow secondary breakup when injected into the elevated cross flow [23] and produce relatively large droplets $[10,22,28]$. Therefore, spray wall impingement occurs and results in a spray cooling flux of several $\mathrm{MW} / \mathrm{m}^{2}$ during the injection duration [29]. Due to the spray cooling effect, liquid film formation occurs below a critical wall temperature as visualized by $[14,24]$. However, the fundamental aspects of the spray wall impingement and the phenomenology of the deposit formation process are not thoroughly reported. Meanwhile, several application oriented papers have clearly pointed out detrimental effects of solid deposits in real applications $[7,9,30,31]$.

In the field of UWS spray impingement, two kinds of studies exist in the literature: single droplet evaporation/impact $[24,32,33]$ or numerical simulation of the spray/wall impact $[2,14,34]$. Multi-stage evaporation behavior of UWS droplets have been observed [32,33]. The first stage is featured by water evaporation following the $D^{2}$ law, thereafter micro-explosion results in more complex behavior. Numerical simulation efforts [2,14] have implemented a regime map into the modelling of the urea spray impingement based on the kinetic properties of droplets and the wall temperature. They have described different modes of single droplet wall impact. To our knowledge so far, no results have been reported concerning the macro properties of droplet impact as a whole spray.

On the other hand, the spray impingement has been studied in diverse applications, like fuel spray impingement [35-37], steel quenching [38] and electronics cooling [39]. Previous studies have indicated that, the impingement flux has the highest influence on the spray impingement heat transfer [38,40-42]. Typical optical techniques, Mie scattering [23] or backlight imaging [24], having described the spray patterns while impacting, are not able to provide quantification of the impinging spray mass load on the wall. This is decisive for the spray wall heat transfer and the following deposit formation. 
The present paper is a systematical investigation of the UWS spray impingement process under dieseltypical conditions. The impingement process is described both qualitatively and quantitatively. The impinging spray mass flux distributions were quantified by using a mechanical patternator. Phase Doppler Anemometry (PDA) was applied to characterize the impinging droplet size distributions under various conditions. Optical visualization experiments were conducted to observe the phenomena associated with the impingement process, such as liquid film formation, urea crystallization and deposit formation. Solid deposits were analyzed by nuclear magnetic resonance spectroscopy. Results of this study provide new insights into the UWS spray impingement process which can be used for the lay-out of efficient aftertreatment systems, and offer ample possibilities for validating numerical simulations.

\section{Experimental Setup and Methods}

Measurements were conducted in a flow lab, which was designed for the experimental investigation of SCR systems as described in detail $[10,28]$. In the present work, a commercial SCR injector was mounted on the top of the measurement chamber, $50^{\circ}$ inclined to the gas flow direction. It was a pressure-driven injector with three $190 \mu \mathrm{m}$ nozzle holes arranged evenly on a $1.9 \mathrm{~mm}$ diameter ring. The injection pressure was regulated to 9 bar.

Optical film visualization experiments were performed to study the phenomena associated with spray impingement on a plate under various exhaust-typical conditions. The stainless steel plate, having an averaged surface roughness of $0.5 \mu \mathrm{m}$, was placed $14 \mathrm{~mm}$ (measured from the front surface) above the channel bottom as shown in Fig. 1. The impinged plate had a dimension of $200 \mathrm{~mm} \times 80 \mathrm{~mm}$ and a thickness of $4 \mathrm{~mm}$. The impingement processes were captured by a high speed CMOS camera (Casio EX-FH100) working at 30 frames per second at a resolution of $640 \times 480$ pixels. The camera was mounted $352 \mathrm{~mm}$ vertically upwards of the impinged plate. The illumination was provided by a LED lamp covered by a milk glass to diffuse light. For all visualization experiments, the injection frequency was set to $1 \mathrm{~Hz}$, while two different injection durations were studied: $60 \mathrm{~ms}$ and $120 \mathrm{~ms}$. The total number of injections was limited to 150 . Adblue (32.5\% urea-water solution) was used as the injection fluid. 


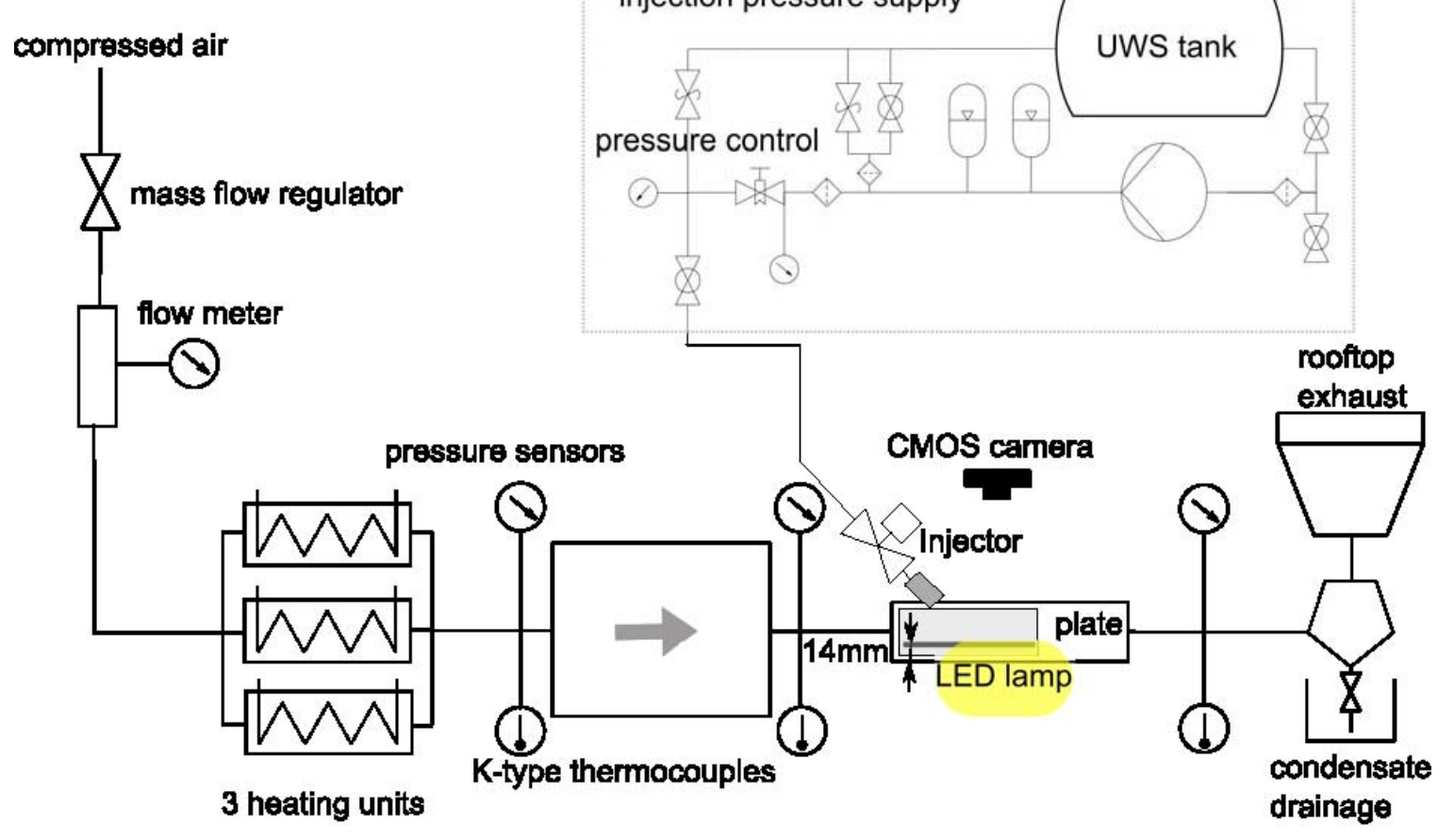

Fig. 1 Schematic diagram of the flow lab with the optical film visualization setup [29].

Image processing was conducted in Matlab for determining the liquid film area. RGB images were firstly converted to grayscale images. The spatial intensity distribution of the grayscale images was corrected by subtracting background image (one image before injection) as shown in Fig. $2 \mathrm{~b}$. Median filter $(5 \times 5)$ was applied to the corrected images to remove the small features on the plate. The processed images were binarized by a threshold value, thus separating the wetted area from the plate (Fig. $2 \mathrm{~d}$ ). Thereafter, every connected region was attributed to a label and only the pixels at the front cone region were kept (Fig. $2 \mathrm{e}$ and f). 
a) grayscale

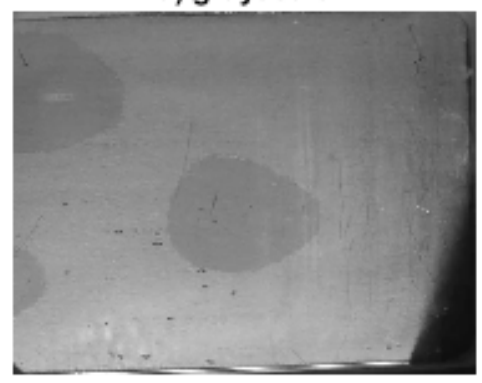

d) threshold binarization

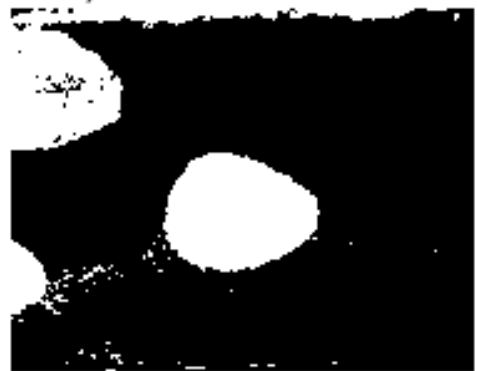

b) background substraction

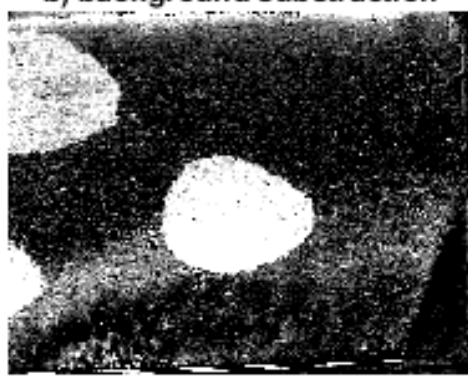

e) remove labels c) median filter

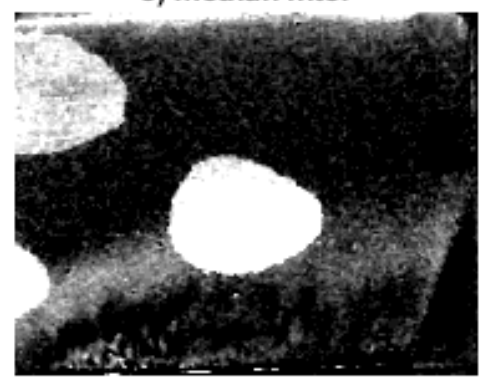

f) edge of the liquid film

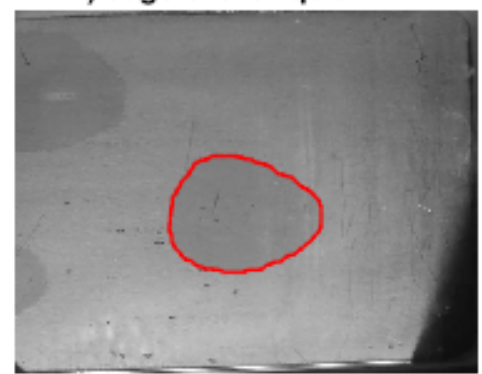

Fig. 2 Image processing for extracting the liquid film area.

Patternator is an in-house developed instrument for measuring spray mass flux distributions. A perforated plate with 24 probes, each of which is connected to a PVC bottle through a silicon hose, was pressed against the channel tightly. A vacuum pump is linked to all collecting bottles through a distributor to create a slight suction for avoiding capillary effects in the hoses. The 24 probes were arranged in three rows of 8 probes each as shown in Fig. 3a. The probe matrix has a spacing distance of $10 \mathrm{~mm}$ in the flow direction and $15 \mathrm{~mm}$ in the transversal direction. Each probe has an inner diameter of $5 \mathrm{~mm}$. To refine the measurement grid, the flow channel was traversed on a two-axis sliding system, while the patternator was fixed on the working table. In this manner, a resolution of $2 \mathrm{~mm} \times 2 \mathrm{~mm}$ was obtained. Each data point was averaged over 1700 injections. The injection strategy was set to $3 \mathrm{~Hz}$ of $150 \mathrm{~ms}$ to speed up the measurement. The injected fluid is demineralized water to avoid blockages in the hoses or probes. The mass flux displayed in results section is calculated as follows:

$$
\dot{m}=\frac{m}{n t_{i n j} A}
$$

where $\dot{m}$ is the mass flux, $m$ the total mass collected per probe, $n$ the number of injections collected, $t_{\text {inj }}$ the duration of each injection and $A$ the probe tip opening area. 


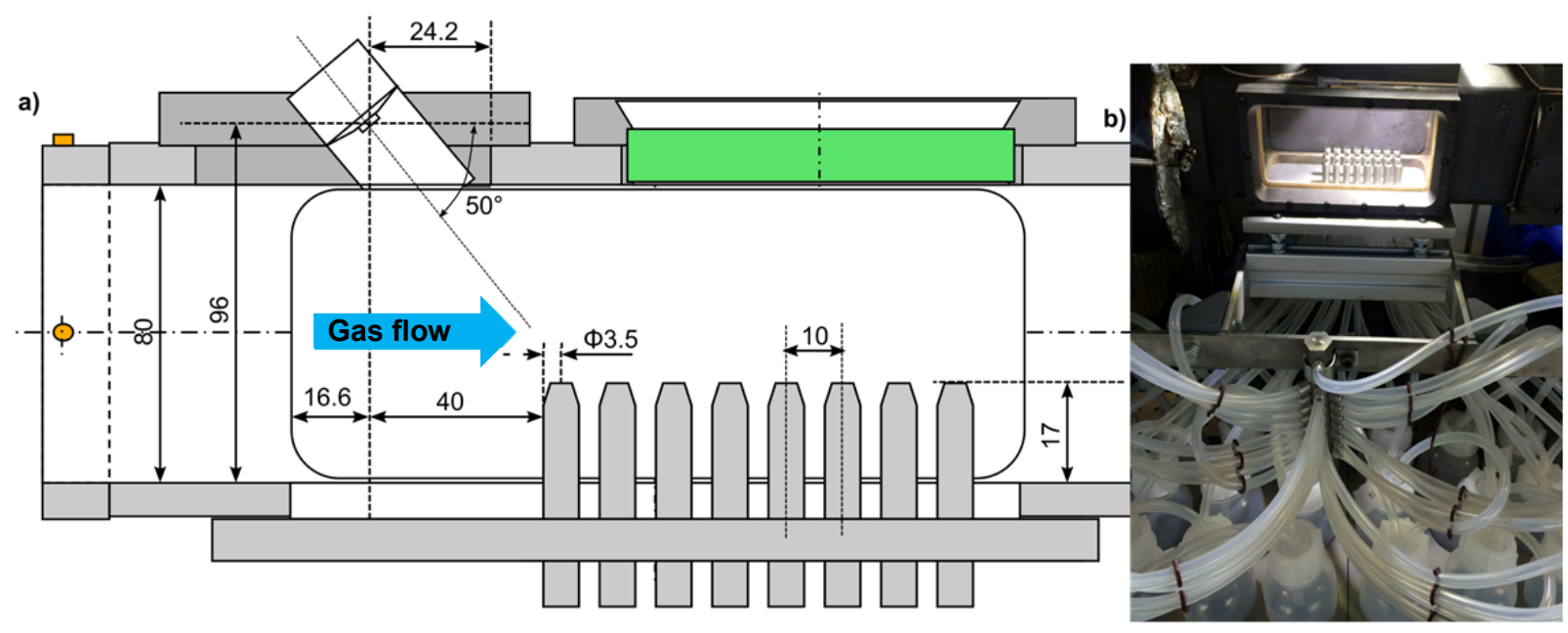

Fig. 3 a) Schematic drawing and b) photograph showing the patternator integrated in the flow channel.

In order to decouple the influence of entrainment and evaporation on the impinging mass fluxes, patternator measurements were performed under iso-temperature and iso-momentum flow conditions as indicated in Tab. 1. For iso-momentum conditions, gas flow momentums were kept the same as that of 200 $\mathrm{kg} / \mathrm{h}$ flow at $20^{\circ} \mathrm{C}$. Therefore, flow rates had to be adjusted at elevated temperatures as follows:

$$
\frac{\dot{m}}{\dot{m}_{\text {amb }}}=\sqrt{\frac{\rho(T)}{\rho\left(T_{\text {amb }}\right)}}
$$

where $\dot{m}$ is the gas mass flow rate, $\rho$ the gas density and amb denotes $20^{\circ} \mathrm{C}$. The corrected flow rates are shown in Tab. 1.

\begin{tabular}{|c|c|c|c|c|c|c|c|c|c|}
\hline & \multicolumn{4}{|c|}{ Iso-temperature conditions } & \multicolumn{4}{c|}{ Iso-momentum conditions } \\
\hline $\mathrm{T}\left[{ }^{\circ} \mathrm{C}\right]$ & 20 & 20 & 20 & 20 & 20 & 150 & 200 & 300 & 400 \\
\hline$\dot{m}[\mathrm{~kg} / \mathrm{h}]$ & 0 & 100 & 200 & 300 & 200 & 167 & 157 & 143 & 132 \\
\hline $\mathrm{\rho v}^{2}\left[\mathrm{~kg} / \mathrm{ms}^{2}\right]$ & 0 & 15.7 & 62.5 & 141.4 & 62.5 & 62.5 & 62.5 & 62.5 & 62.5 \\
\hline
\end{tabular}

Tab. 1 Gas flow conditions during the patternator measurements.

${ }^{1} \mathrm{H}$ and ${ }^{13} \mathbf{C}$ Nuclear magnetic resonance (NMR) spectra were recorded at 400.1 and 100.6 , respectively on a Bruker Avance III 400 NMR spectrometer (Bruker Biospin AG, Fällanden, Switzerland). The sample analyzed by NMR were the solid deposits, which were collected from the plate after the optical experiment under the condition of $300^{\circ} \mathrm{C}, 100 \mathrm{~kg} / \mathrm{h}$ and $1 \mathrm{~Hz}$ of $120 \mathrm{~ms}$. The NMR experiments were performed at 298 $\mathrm{K}$ using the Bruker standard pulse programs and parameter sets on a $5 \mathrm{~mm}$ CryoProbe ${ }^{\mathrm{TM}}$ Prodigy probe equipped with z-gradient applying $90^{\circ}$ pulse lengths of $11.4 \mu \mathrm{s}\left({ }^{1} \mathrm{H}\right)$ and $10.0 \mu \mathrm{s}\left({ }^{13} \mathrm{C}\right)$. The ${ }^{13} \mathrm{C}$ NMR spectra were recorded applying power gated ${ }^{1} \mathrm{H}$ decoupling using $30^{\circ}$ excitation pulses and relaxations 
delays of $1 \mathrm{~s}$ allowing a good signal to noise of the minor components in a relatively short experimental time (up to 1 day of measurement time). Although the recording conditions were not really quantitative, we observed only small deviations from an experiment where we applied $30 \mathrm{~s}$ relaxations delays. The NMR chemical shifts $(\delta)$ were calibrated to the ${ }^{1} \mathrm{H}$ NMR resonance at $4.79 \mathrm{ppm}$ in the case of $\mathrm{D}_{2} \mathrm{O} / \mathrm{NaOD}$ solutions and ${ }^{13} \mathrm{C}$ chemical shifts were calibrated externally to the signal of tetramethysilane at $0.0 \mathrm{ppm}$. Since a considerable dependency of resonance positions on $\mathrm{pH}$ values and concentrations were observed, signal assignments of individual resonances were performed by addition of small amounts of all possible chemical species (urea, biuret, triuret, cyanuric acid, ammelide, ammeline or melamine [43]) to the sample solution of interest. From a line shape analysis of the ${ }^{13} \mathrm{C}$ NMR spectra the relative amounts of all individual resonances were determined by non-linear least-square fits of all signals of interest using the line shape simulation software "DMFIT" [44]. Subsequently, the sample composition can be evaluated using the following equations, where Int(i) is the relative signal intensity of species i, "No. (C)" the number of carbons contributing to the signal and MW(i) the molecular weight of the individual species (see Tab. 2):

$$
x(i)=\frac{\frac{\operatorname{lnt}(i)}{\operatorname{No}((c)} * M W(i)}{\sum \frac{\operatorname{Int}(i)}{\operatorname{No}(c)} * M W(i)}[w t / w t-\%]
$$

\begin{tabular}{ccccccc} 
comp. & & urea & biuret & $\begin{array}{c}\text { triuret } \\
1^{\text {st }} \text { site }\end{array}$ & $\begin{array}{c}\text { triuret } \\
2^{\text {nd }} \text { site }\end{array}$ & melamine \\
\hline formula & & $\mathrm{CH}_{4} \mathrm{~N}_{2} \mathrm{O}$ & $\mathrm{C}_{2} \mathrm{H}_{5} \mathrm{~N}_{3} \mathrm{O}_{2}$ & $\mathrm{C}_{3} \mathrm{H}_{6} \mathrm{~N}_{4} \mathrm{O}_{3}$ & $\mathrm{C}_{3} \mathrm{H}_{6} \mathrm{~N}_{4} \mathrm{O}_{3}$ & $\mathrm{C}_{3} \mathrm{H}_{6} \mathrm{~N}_{6}$ \\
$\mathrm{MW}$ & {$[\mathrm{g} / \mathrm{mol}]$} & 60.056 & 103.081 & 146.106 & 146.106 & 126.123 \\
$\delta^{13} \mathrm{C}$ & {$[\mathrm{ppm}]$} & 162.8 & 164.4 & 162.9 & 161.9 & 166.7 \\
No of C & & 1 & 2 & 2 & 1 & 3 \\
& & & & & & \\
comp. & & ammeline & ammeline & ammelide & ammelide & cyanuric \\
& & $1^{\text {st }}$ site & $2^{\text {nd }}$ site & $1^{\text {st }}$ site & $2^{\text {nd }}$ site & \\
\hline formula & & $\mathrm{C}_{3} \mathrm{H}_{5} \mathrm{~N}_{5} \mathrm{O}$ & $\mathrm{C}_{3} \mathrm{H}_{5} \mathrm{~N}_{5} \mathrm{O}$ & $\mathrm{C}_{3} \mathrm{H}_{4} \mathrm{~N}_{4} \mathrm{O}_{2}$ & $\mathrm{C}_{3} \mathrm{H}_{4} \mathrm{~N}_{4} \mathrm{O}_{2}$ & $\mathrm{C}_{3} \mathrm{H}_{3} \mathrm{~N}_{3} \mathrm{O}_{3}$ \\
$\mathrm{MW}$ & {$[\mathrm{g} / \mathrm{mol}]$} & 127.107 & 127.107 & 128.091 & 128.091 & 129.075 \\
$\delta^{13} \mathrm{C}$ & {$[\mathrm{ppm}]$} & 171.6 & 168.3 & 169.1 & 166.1 & 167.2 \\
No of C & & 1 & 2 & 1 & 2 & 3
\end{tabular}




\section{Results and Discussion}

\subsection{Impinging Spray Mass Flux Distributions}

The 3-hole injector has been completely characterized using the mechanical patternator. Measurements were performed within a rectangular field, $84 \mathrm{~mm}$ in the flow direction $\mathrm{x}$ and $65 \mathrm{~mm}$ in the transversal direction z under ambient condition $\left(20^{\circ} \mathrm{C}, 0 \mathrm{~kg} / \mathrm{h}\right)$ and under exhaust-typical conditions. The coordinates indicated in Fig. 4 to Fig. 5 are the distances from the injector nozzle exit along $x$ and $z$ directions. Detailed spatially-resolved mass flux distribution provided in Fig. 4 reveals that there are three distinct impingement regions, each corresponding to one hole of the injector. This coincides with the spray footprints as shown in Fig. 10. The spray patterns produced by each hole of the injector are slightly different, and the maximum impingement rate $0.0212 \mathrm{~kg} /\left(\mathrm{h} * \mathrm{~mm}^{2}\right)$ is found in the upstream spray cone. The acquired data points were fitted using the cubic interpolation function and integrated within the whole field, which resulted in an impingement rate of $7.44 \mathrm{~kg} / \mathrm{h}$. The nominal injection rate, which is estimated by collecting the injected mass over 3000 injections, is $7.02 \mathrm{~kg} / \mathrm{h}$. It means that the patternator method produces an error of $6 \%$ in the impingement rate. The spray dispersion characteristics are quantified in Tab. 3, showing the sizes of the areas. $90 \%$ of the total impinged mass is contained in a region of $2340 \mathrm{~mm}^{2}$, which gives an average film thickness of $119 \mu \mathrm{m}$ for a single injection under the assumption that all droplets are deposited on the impinged plate. $50 \%$ of the total mass is contained in an area of $386 \mathrm{~mm}^{2}, 16.5 \%$ of $2340 \mathrm{~mm}^{2}$, which indicates that the spray mass is concentrated in the core and fades out quickly towards the periphery.

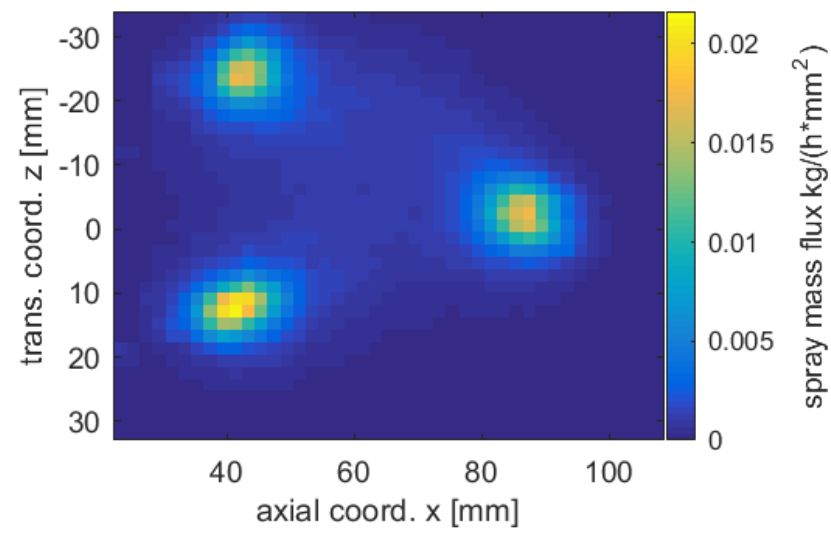

Fig. 4 Mass flux distribution with a resolution of $2 \mathrm{~mm} \times 2 \mathrm{~mm}$ on the plane $79 \mathrm{~mm}$ apart from the injector nozzle exit at ambient condition $\left(20^{\circ} \mathrm{C}, 0 \mathrm{~kg} / \mathrm{h}\right)$. 


\begin{tabular}{|c|c|c|c|c|}
\hline Percentage of the impinged mass & $20 \%$ & $50 \%$ & $75 \%$ & $90 \%$ \\
\hline Area at ambient condition $\left[\mathrm{mm}^{2}\right]$ & 86.3 & 385.8 & 1276.6 & 2337.9 \\
\hline Area at $300^{\circ} \mathrm{C}, 200 \mathrm{~kg} / \mathrm{h}\left[\mathrm{mm}^{2}\right]$ & 53.4 & 181.1 & 384.4 & 663.3 \\
\hline
\end{tabular}

Tab. 3 Area occupied by different mass fraction at ambient condition and at $300{ }^{\circ} \mathrm{C} 200 \mathrm{~kg} / \mathrm{h}$.

The mass flux distribution at ambient condition serves as a reference case, while mass flux distributions under exhaust typical conditions are of more significance for real applications. The set of 1505 mass flux measurements at flow condition of $300{ }^{\circ} \mathrm{C}$ and $200 \mathrm{~kg} / \mathrm{h}$ is displayed in Fig. 5. The three distinct spray cones are clearly identified in Fig. 5 , while the peak flux in the upstream cone goes down for $44 \%$ to $0.0119 \mathrm{~kg} /\left(\mathrm{h} * \mathrm{~mm}^{2}\right)$. Moreover, the small droplets in the spray periphery are completely entrained by the gas flow. The sizes of the regions enclosing $20 \%, 50 \%, 75 \%, 90 \%$ of the total impinged mass at $300^{\circ} \mathrm{C}$ $200 \mathrm{~kg} / \mathrm{h}$ are also provided in Tab. 3. The spray is getting less dispersed compared to that at ambient. The periphery of the spray is more affected by the gas flow than the spray center.

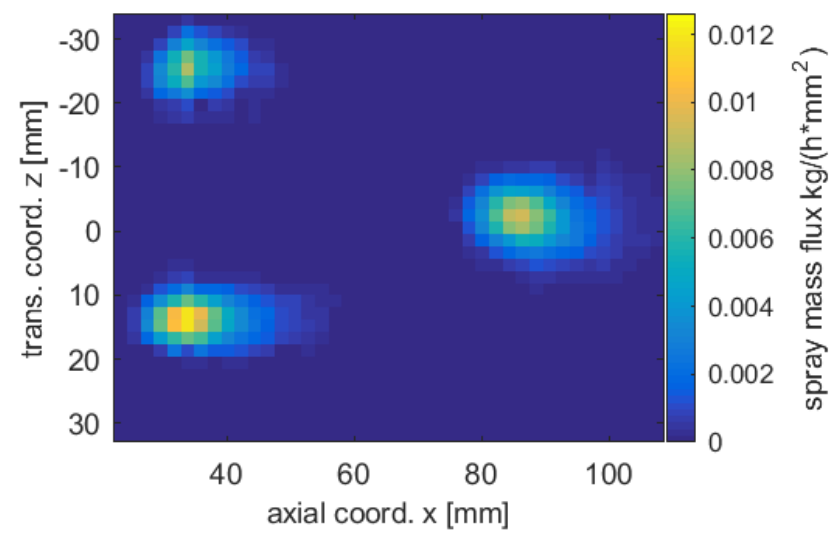

Fig. 5 Mass flux distribution with a resolution of $2 \mathrm{~mm} \times 2 \mathrm{~mm}$ on the plane $79 \mathrm{~mm}$ apart from the injector nozzle exit at the flow condition of $300^{\circ} \mathrm{C}, 200 \mathrm{~kg} / \mathrm{h}$.

The dispersion characteristics are quantified in Fig. 6, showing non-normalized probability density functions (PDF) and cumulative distribution functions (CDF) of the mass flux measurements at ambient and elevated flow conditions. At ambient condition, mass flux measurements range from 0 to $0.0212 \mathrm{~kg} /$ $\mathrm{kg} /\left(\mathrm{h} \times \mathrm{mm}^{2}\right)$, with an average of $0.0013 \mathrm{~kg} /\left(\mathrm{h} * \mathrm{~mm}^{2}\right)$ and a standard deviation of $0.0026 \mathrm{~kg} /\left(\mathrm{h} * \mathrm{~mm}^{2}\right)$, while at elevated flow condition mass flux measurements range from 0 to $0.0119 \mathrm{~kg} /\left(\mathrm{h} * \mathrm{~mm}^{2}\right)$, with an average of $0.0012 \mathrm{~kg} /\left(\mathrm{h} * \mathrm{~mm}^{2}\right)$ and a standard deviation of $0.0021 \mathrm{~kg} /\left(\mathrm{h} * \mathrm{~mm}^{2}\right)$. At elevated flow condition, integrating the mass flux measurements over the total area gives an impingement rate of $2.50 \mathrm{~kg} / \mathrm{h}$. The mass reduction of $64.4 \%$ compared to the nominal injection rate is due to the droplet entrainment by the gas 
flow and the droplet evaporation in the gas flow. The spray entrainment and evaporation are quantified and modeled as a function of gas flow momentum and gas flow temperature respectively as indicated in Fig. 8 and Fig. 9.

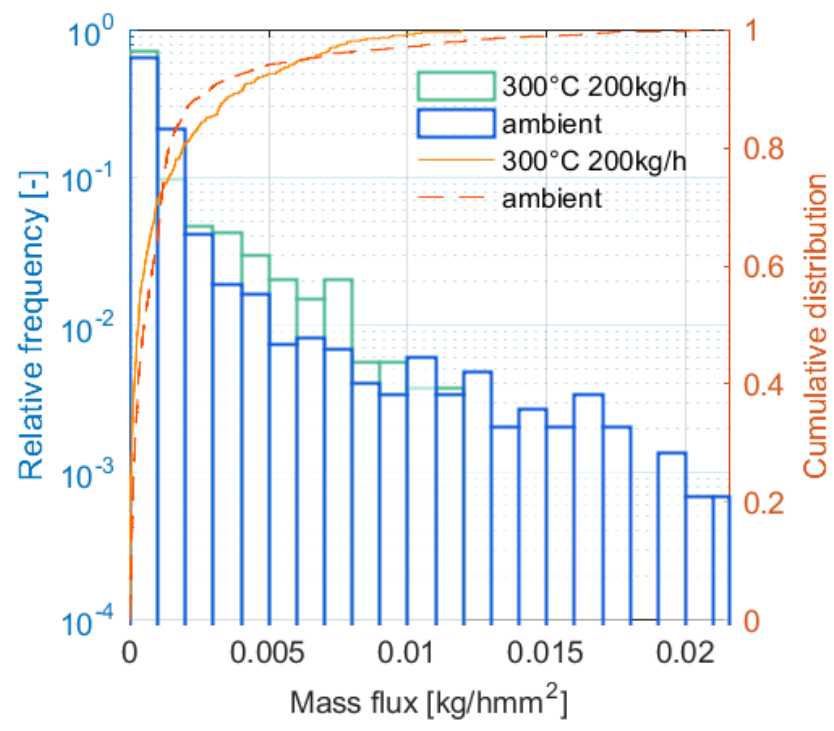

Fig. 6 Relative frequency and cumulative distribution of mass flux measurements at ambient condition and at the flow condition of $300{ }^{\circ} \mathrm{C} 200 \mathrm{~kg} / \mathrm{h}$.

Having evidenced an impinging mass flow rate reduction due to entrainment and evaporation, droplet sizes distributions (stagnant and $300{ }^{\circ} \mathrm{C} 200 \mathrm{~kg} / \mathrm{h}$ ) from our previous studies [28,29] have been compared to understand the influence of entrainment and evaporation on the impinging droplets depending on the diameter. The droplet distributions were measured with PDA, the setup of which is elaborated in $[10,19,28]$. For the comparison, the non-normalized impinging droplet PDF for the $300{ }^{\circ} \mathrm{C} 200 \mathrm{~kg} / \mathrm{h}$ case is multiplied by a scaling factor of 0.608 , which is the ratio of the impinging mass flow rate of the $300{ }^{\circ} \mathrm{C} 200$ $\mathrm{kg} / \mathrm{h}$ case to that of ambient condition. It is derived by integrating the patternator measurements over the same domain as the PDA measurement region. The difference of these two PDF distributions represents the mass reduced by the flow (both entrainment and evaporation) for each diameter class as displayed in Fig. 7. The hot flow influences mainly droplets below $90 \mu \mathrm{m}$, while its influence on bigger droplets is weak. From the CDFs on the right-hand axis, the cumulative mass difference for droplets below $90 \mu \mathrm{m}$ is 0.283 , whereas the total difference is 0.392 ( 1 - the scaling factor). Moreover, the impinging mass percentage (the impinging mass of the $300{ }^{\circ} \mathrm{C} 200 \mathrm{~kg} / \mathrm{h}$ case to that of ambient condition) is gradually increasing with increasing diameter for droplets less than $90 \mu \mathrm{m}$. For droplets below $20 \mu \mathrm{m}$, the hot flow entrains or 
evaporates almost everything, whereas $60 \%$ of the mass is still impinging from droplets between $73 \mu \mathrm{m}$ to $90 \mu \mathrm{m}$.

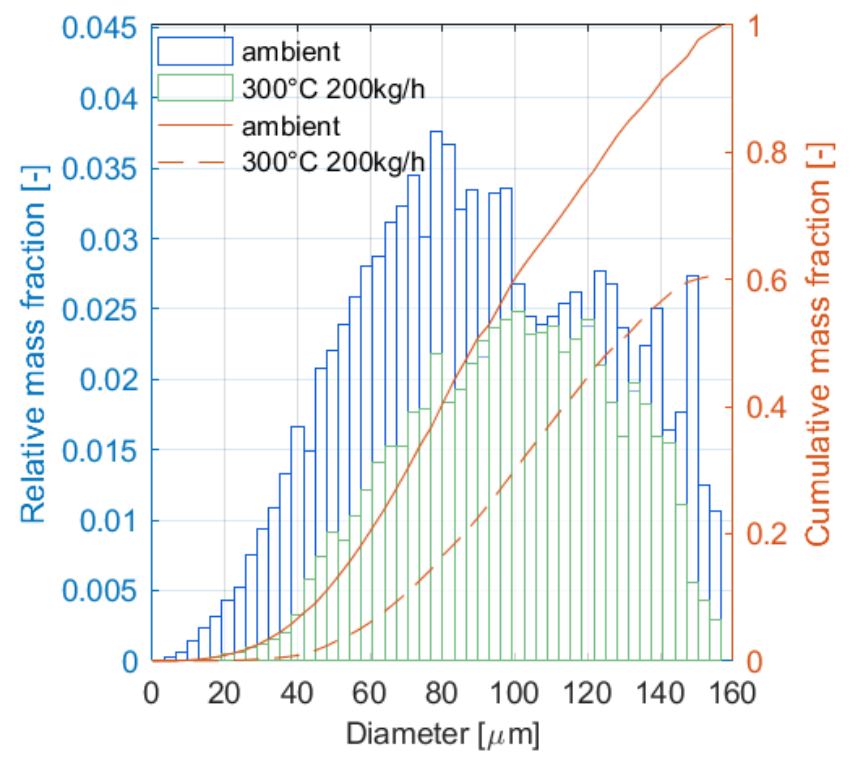

Fig. 7 Droplet mass distributions at ambient condition and at the flow condition of $300{ }^{\circ} \mathrm{C} 200 \mathrm{~kg} / \mathrm{h}$.

With the patternator experiments the spray part impinges on the wall has been quantified. In addition, the results have been used to quantify the entrained and evaporated part of the spray. To determine the spray entrainment level as a function of gas flow momentum, the gas flow was kept under non-evaporating conditions for this series of measurements. The flow temperature was set to $20^{\circ} \mathrm{C}$ and the flow rate was varied among stagnant, $100 \mathrm{~kg} / \mathrm{h}, 200 \mathrm{~kg} / \mathrm{h}$, and $300 \mathrm{~kg} / \mathrm{h}$. The blue points in Fig. 8 show the reductions in the impingement mass, integrated over a rectangle area of the same size around the spray peak, for different gas flow momentums. The data can be fitted to a logarithmic function of the gas flow momentum, which takes the following form:

$$
\text { Ent }=0.04735 \cdot \ln \left(0.8321 \cdot \rho v^{2}+1\right)
$$

Ent denotes the entrainment level and $\rho v^{2}$ is the gas flow momentum. R-squared of this fit is 0.9995 . 


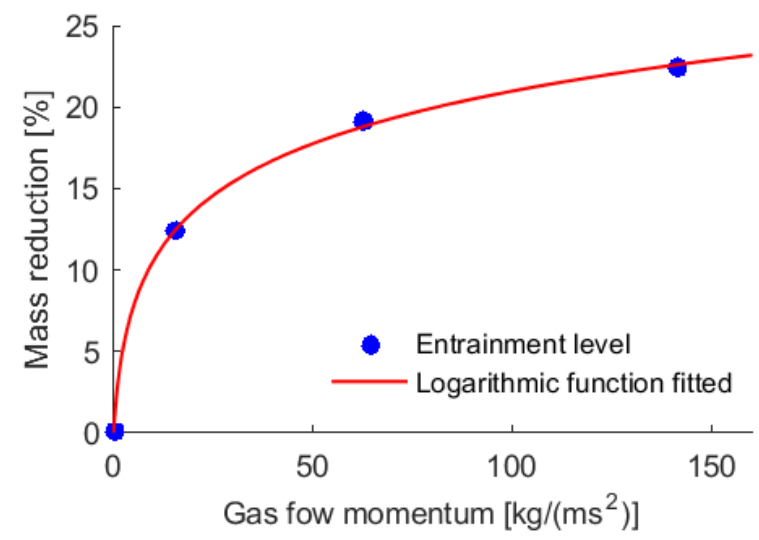

Fig. 8 Entrainment as a function of gas flow momentum.

To evaluate the spray evaporation portion as a function of gas flow temperature, the gas flow momentum was kept constant at $62.5 \mathrm{~kg} / \mathrm{ms}^{2}$. The flow temperature was increased from ambient to $400^{\circ} \mathrm{C}$. The blue points in Fig. 9 indicate the impingement mass reductions for various flow temperatures. The green dots were obtained by subtracting the entrainment level $(19.13 \%)$ at $62.5 \mathrm{~kg} / \mathrm{ms}^{2}$ from the overall reductions. The red curve is a fitted through the green points, which takes the following form:

$$
E v a=0.006331 \sqrt{T-100}+0.1886
$$

Eva denotes the evaporation resulting mass reduction and $T$ the gas flow temperature. The spray is characterized by a wide range of droplets from 0 to $160 \mu \mathrm{m}$. Smaller droplets are more likely to be entrained and evaporated. The diameter of the smallest droplet after breakup that still reaches the plate is denoted as the critical evaporation or entrainment diameter. Assuming a sphere evaporation model in hot surroundings, the critical evaporation diameter scales with the square root of the temperature difference between the gas flow temperature and the liquid saturation temperature. However, droplets which are initially evaporated below the critical entrainment diameter can be entrained by the gas flow as well. The green part in Fig. 9 is rather a co-influence by both entrainment and evaporation, referred as evaporation resulting impinging mass reduction.

The impinging spray mass flux is one of the key parameters governing the spray/wall interaction process. The results show clearly that the impingement of such low pressure sprays is unavoidable regardless of exhaust flow rates and temperatures. On the other hand, Fig. 7 implies that finer sprays would reduce the wall impingement. Finer sprays could be achieved by either raising the injection pressure or decreasing 
the nozzle diameter, or both. Furthermore, the results can be used in: I) calibration of numerical codes aiming for modelling the wall impingement behavior, II) assessing the amount of wall heating necessary to maintain the wall temperature according to the impinging mass (Tab. 4).

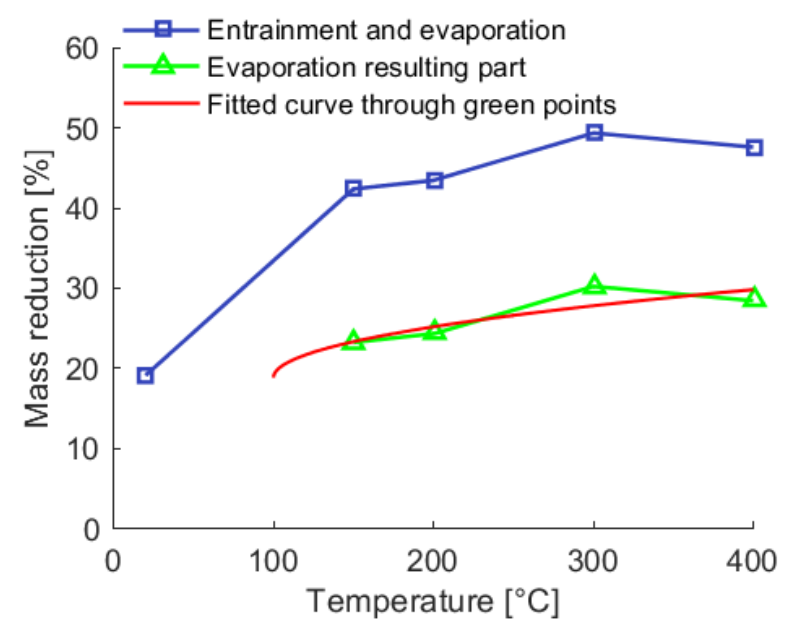

Fig. 9 Evaporation as a function of gas flow temperature.

\subsection{Spray Impingement Phenomenology}

Optical high speed camera experiments have been performed in order to analyze the spray impingement behavior. The gas flow condition for images shown in Fig. 10 to Fig. 17 is $300{ }^{\circ} \mathrm{C}$ and $100 \mathrm{~kg} / \mathrm{h}$, the gas flow direction is from left to right in the image. SOI stands for the time instant of the start of the first injection, whereas EOI denotes the time instant of the end of the last injection.

Following the first injection the spray impinges on the hot plate (plate temperature similar to the flow temperature, i.e. $300^{\circ} \mathrm{C}$ ) resulting in three separate liquid film areas, as shown in Fig. 10a. The spray/wall interaction behavior is dominated by rebound and thermal breakup as long as the plate temperature remains above $280^{\circ} \mathrm{C}$ (according to Kuhnke [34] and Liao et al. [29]). This is strongly evidenced by the white smoke emerging in the downstream of the three impingement areas in Fig. 10a, consisting of urea enriched rebounding droplets, since water has partly evaporated during impingement. During each injection (duration $120 \mathrm{~ms}$ ) the liquid film area increases reaching a maximum shortly after the end of this injection. Thereafter, in the remaining 880 ms until the next injection starts, the liquid film retracts reaching a minimum. However, the liquid film areas increase from injection to injection (Fig. 10b) leading roughly after 20 injections to a merging of the three films as can be seen in Fig. 10c. This evidences that 
evaporating liquid between two injections is significantly less in respect to the impinging liquid during injection.

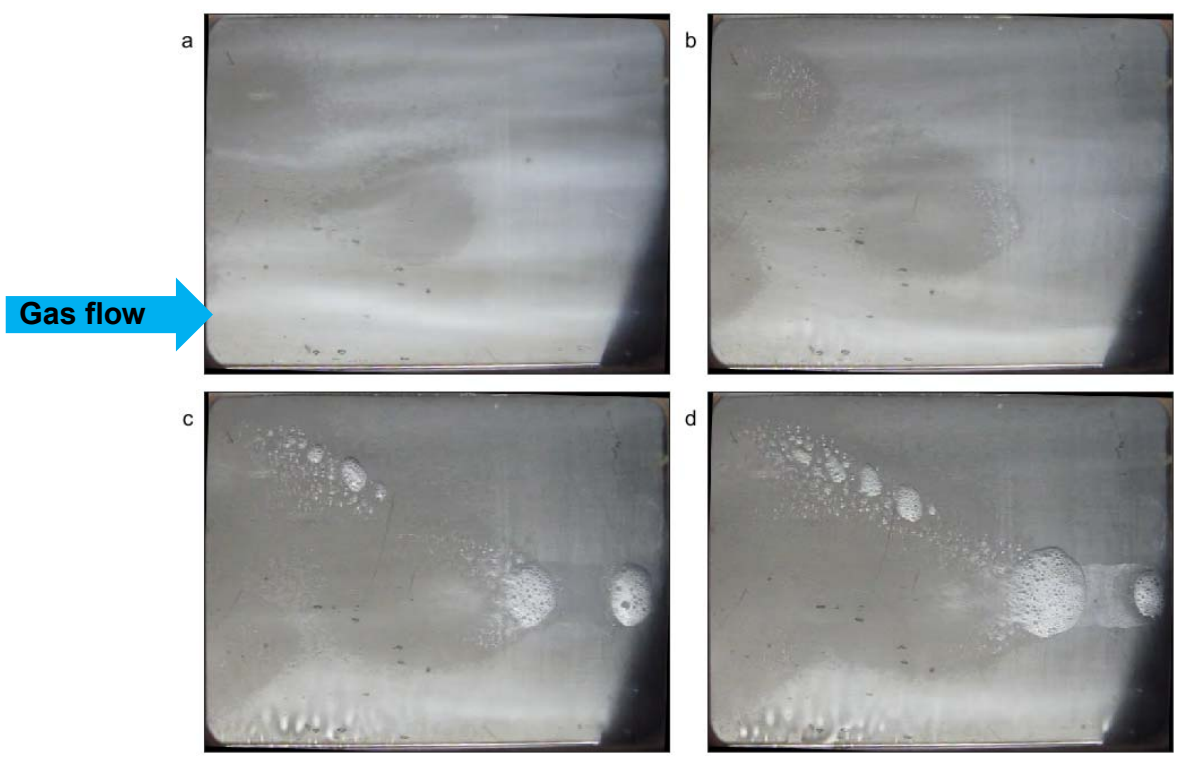

Fig. 10 First stage of impingement a) SOI, b) SOI+10s, c) SOI+26s, d) SOI+31s.

Local evaporation is evidenced as bubble formation already in Fig. 10b, more discernible in Fig. 10c and d in the downstream of the impingement areas. The impingement areas are strongly cooled down as shown by Liao et al [23]. The liquid accumulated here is being transported downstream by the momentum of each injection (and possibly partly by the gas flow), here the plate is not cooled as much as on the impingement area leading to the evaporation of water. This phenomenon is more strongly pronounced after the three liquid footprints merge (Fig. 10c and d). Clearly discernible is the extension of the liquid film as well as the area of water evaporation on its margins.

Image processing delivered the liquid film area evolution over time before merging as shown in Fig. 11a. The maximum liquid film areas are found right after each injection ending, while minimum film areas before each injection beginning. However, they both increase with time at a similar rate of $50 \mathrm{~mm}^{2} / \mathrm{s}$, as indicated by the slopes in Fig. 11a. A series of experiments with half of the injection duration (i.e. $60 \mathrm{ms)}$ and identical gas flow conditions (Fig. 11b) resulted in much slower liquid film area increase rate, $15 \mathrm{~mm}^{2} / \mathrm{s}$ in average. With halving the injection duration the impinging mass for each injection is lower; therefore, the liquid film area increases more slowly. 

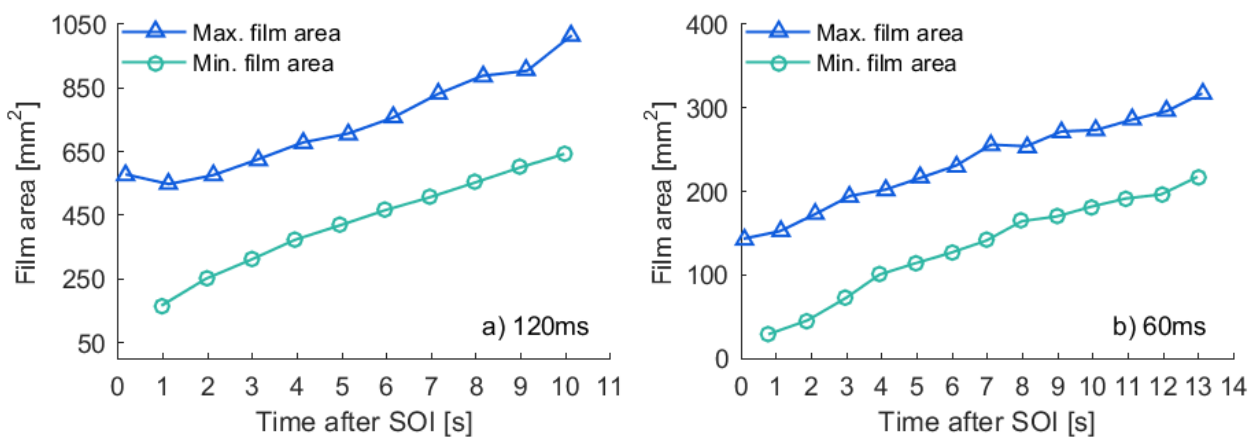

Fig. 11 Initial liquid film area evolution before liquid film merging a) $300^{\circ} \mathrm{C}, 100 \mathrm{~kg} / \mathrm{h}, 120 \mathrm{~ms}$ of $1 \mathrm{~Hz} \mathrm{b)} 300{ }^{\circ} \mathrm{C}$, $100 \mathrm{~kg} / \mathrm{h}, 60 \mathrm{~ms}$ of $1 \mathrm{~Hz}$

There are two effects to be considered as shown in Fig. 12: 1) the liquid film expansion during each injection, which is due to the new impinging liquid and 2) the liquid film retraction between two injections, which is due to the liquid evaporation. The liquid film expansion is derived by the difference between the maximum liquid film area of each injection and the minimum liquid film area of the previous injection. The liquid film retraction is derived by the difference between the maximum and minimum liquid film areas of the same injection. The former could be used for estimating the average liquid film thickness (the impinging mass of each injection divided by the liquid film expansion area and the liquid density), while the latter for estimating the heat extracted from the plate between two injections.
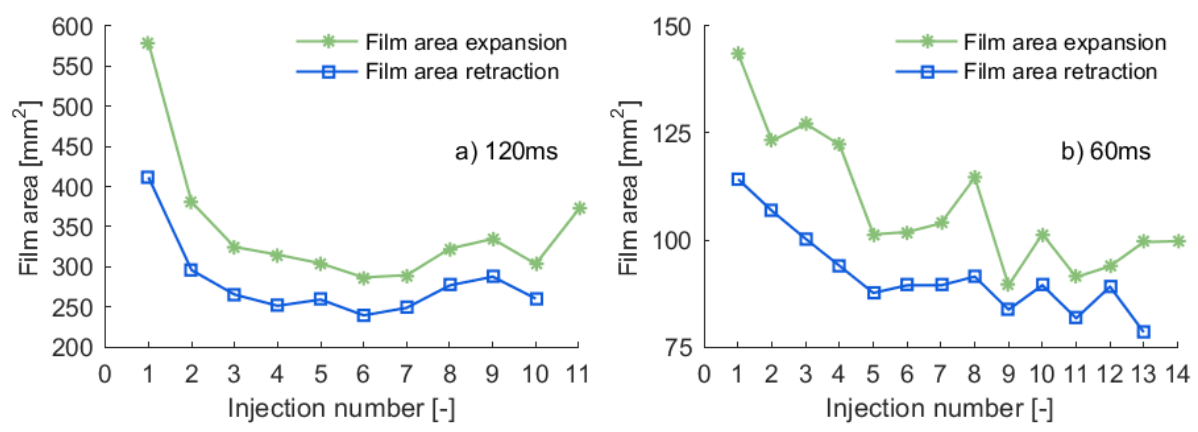

Fig. 12 Liquid film area expansion and retraction a) $300^{\circ} \mathrm{C}, 100 \mathrm{~kg} / \mathrm{h}, 120 \mathrm{~ms}$ of $1 \mathrm{~Hz} \mathrm{b)} 300{ }^{\circ} \mathrm{C}, 100 \mathrm{~kg} / \mathrm{h}, 60 \mathrm{~ms}$ of $1 \mathrm{~Hz}$

Using Eq. (3) and Eq. (4), the entrainment and evaporation levels at the flow condition of $300{ }^{\circ} \mathrm{C}, 100 \mathrm{~kg} / \mathrm{h}$ are $12.4 \%$ and $28.7 \%$, respectively. Knowing the injection rate of $7.2 \mathrm{~kg} / \mathrm{h}$ (based on the manufacturer specification), the impinging mass per injection for the $120 \mathrm{~ms}$ injection duration case is $0.1414 \mathrm{~g}$ and $0.0707 \mathrm{~g}$ for the $60 \mathrm{~ms}$ case. Assuming all impinging liquid mass is deposited and local evaporation during injection is negligible, the average film thickness is estimated at $388 \mu \mathrm{m}$ for the $120 \mathrm{~ms}$ injection duration 
case and $611 \mu \mathrm{m}$ for the $60 \mathrm{~ms}$ injection duration case. These can be considered as the upper limits. Using the average film thickness and the average film retraction area between two injections (Fig. 12b), the evaporated mass per injection is deduced, and thus the heat extracted per injection from the plate is estimated at 155J. This leads to an average heat flux of $1.79 \mathrm{MW} / \mathrm{m}^{2}$. In our previous study [29] infared thermography was used, the heat extracted under similar conditions was estimated at $94 \mathrm{~J}$. Based on this heat extraction and the average film retraction area (Fig. 12b), the average film thickness is estimated at $370 \mu \mathrm{m}$. Numerical simulations $[14,19]$ reported wall film thicknesses from 70 to $200 \mu \mathrm{m}$, while it should be taken into account that the injection and flow conditions are not directly comparable. To our knowledge so far, no further studies reported liquid film thicknesses under comparable conditions.

\begin{tabular}{|c|c|c|c|}
\hline & $\begin{array}{c}\text { Average film thickness } \\
{[\mu \mathrm{m}]}\end{array}$ & Heat extracted [J] & Heat flux [MW/m2] \\
\hline Present study & 611 & 155 & 1.79 \\
\hline Liao et. al. [29] & 370 & 94 & 1.09 \\
\hline Numerical study [19] & 200 & 51 & 0.59 \\
\hline
\end{tabular}

Tab. 4 Estimated film thickness before liquid film merging and the comparison to numerical simulation [19].

At a later period, urea crystalizes intermittently at some locations as identified in Fig. 13 between two injections. Water is primarily evaporated during the multi-stage evaporation process of UWS droplets $[32,33]$. Therefore, the liquid film on the impinged plate is composed of a urea-enriched solution. When the plate temperature drops below the saturation point, urea crystalizes locally. The next injection with higher concentration of water subsequently dissolves the urea crystals as it arrives.

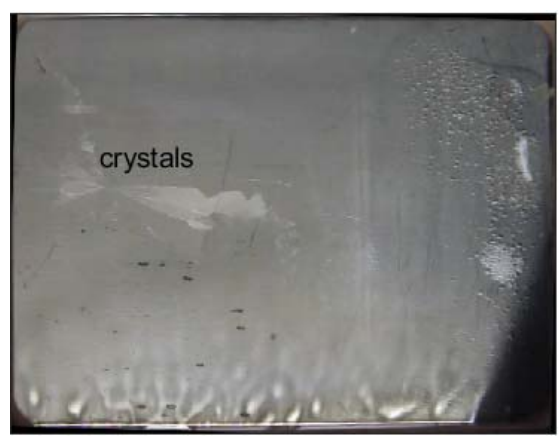

Fig. 13 Solid urea crystalizes during the injection interval at a later period (SOI+131s).

After the end of the last injection, urea begins to crystalize from the urea-enriched liquid film in the 
periphery of the spray impinged area, reaching the maximum amount at EOI+9s (Fig. 14b). Thereafter, urea crystals start melting as a consequence of the temperature recovery of the plate and disappear completely at EOI+26s (Fig. 14c and d). The crystal area evolution after EOI is quantified in Fig. 15. The image processing was performed according to the description under Section 2. The urea crystals spread most to $1117 \mathrm{~mm}^{2}$. Furthermore, the urea crystallization speed is almost 2 times of the urea melting speed. The crystallization temperature for $80 \%$ urea-water solution is $80{ }^{\circ} \mathrm{C}$. Therefore, the crystallization phase here is mainly driven by the process kinetics. However, the melting phase is strongly dependent on the heat transfer rate. The fitted orange curve shown in Fig. 15 follows a $3^{\text {rd }}$ order polynomial function, which takes the following form:

$$
A=0.00001354 t^{3}-0.02249 t^{2}+9.27 t+15.27
$$

where $A$ is the crystal area, and $t$ is the time after EOI.
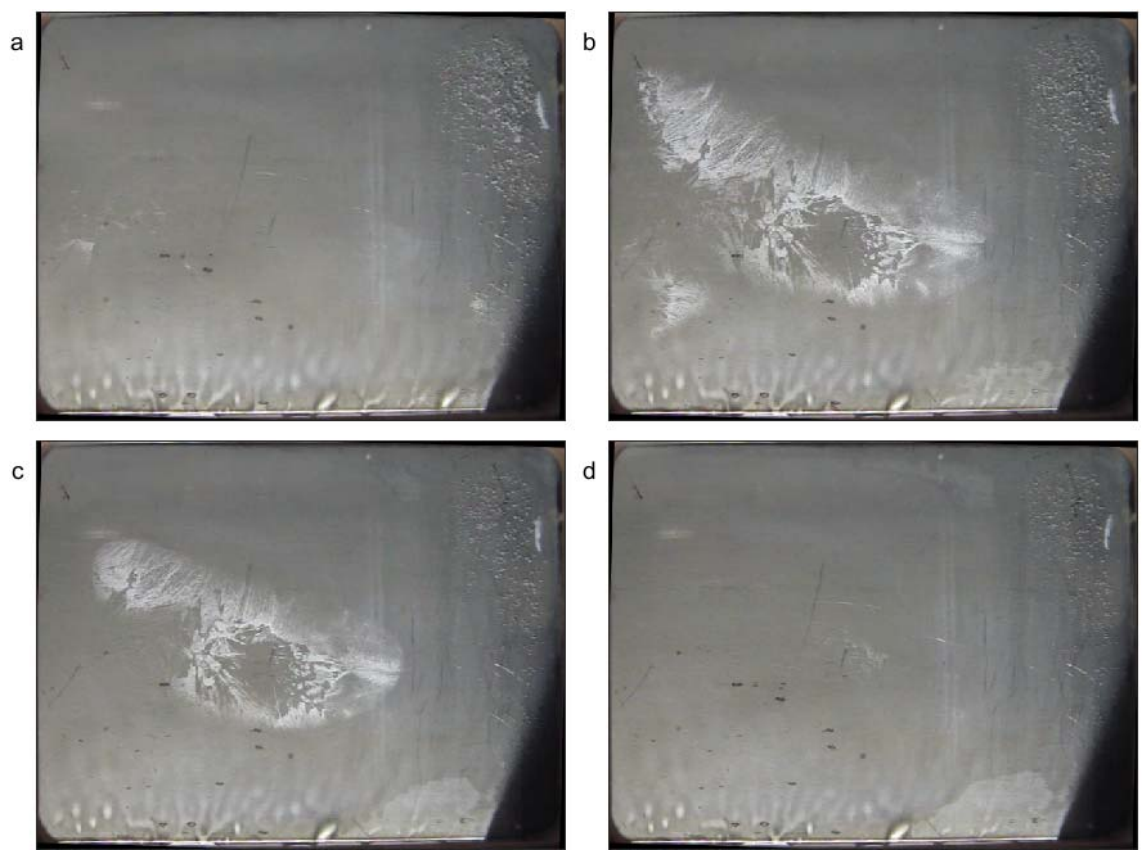

Fig. 14 After the injector closes permanently, urea firstly crystalizes and then melts, followed by the liquid film evaporation a) EOI, b) EOI+9s, c) EOI+17s, d) EOI+26s. 


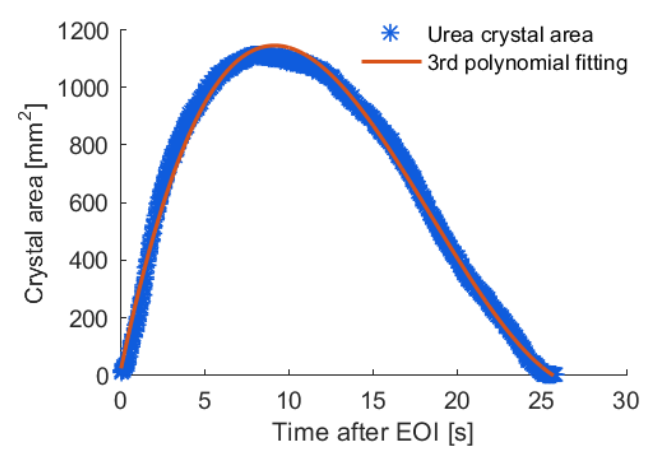

Fig. 15 Urea crystallization and melting area evolution after the end of injection.

At $\mathrm{EOI}+23 \mathrm{~s}$, the urea-enriched film starts evaporating from the upstream side, from which the hot gas flow is coming. Fig. 16a shows the co-existence of urea crystal melting and liquid film evaporation. The evaporation front propagates from upstream to downstream and from the plate periphery to the plate center as displayed in Fig. 16a to c. At EOI+132s (Fig. 16d), the liquid film is completely evaporated in the impinged region, where no deposit is evidenced. However, white permanent deposits start forming in the merged film tip. This deposit formation site is more downstream than the impingement region. Fig. 17b displays the final state of the permanent deposits on the plate after the liquid is completely evaporated. If the injection duration is shortened, the deposit formation site is located more upstream as shown in Fig. 17a. Decreased injection momentum drives the liquid accumulation region less downstream.
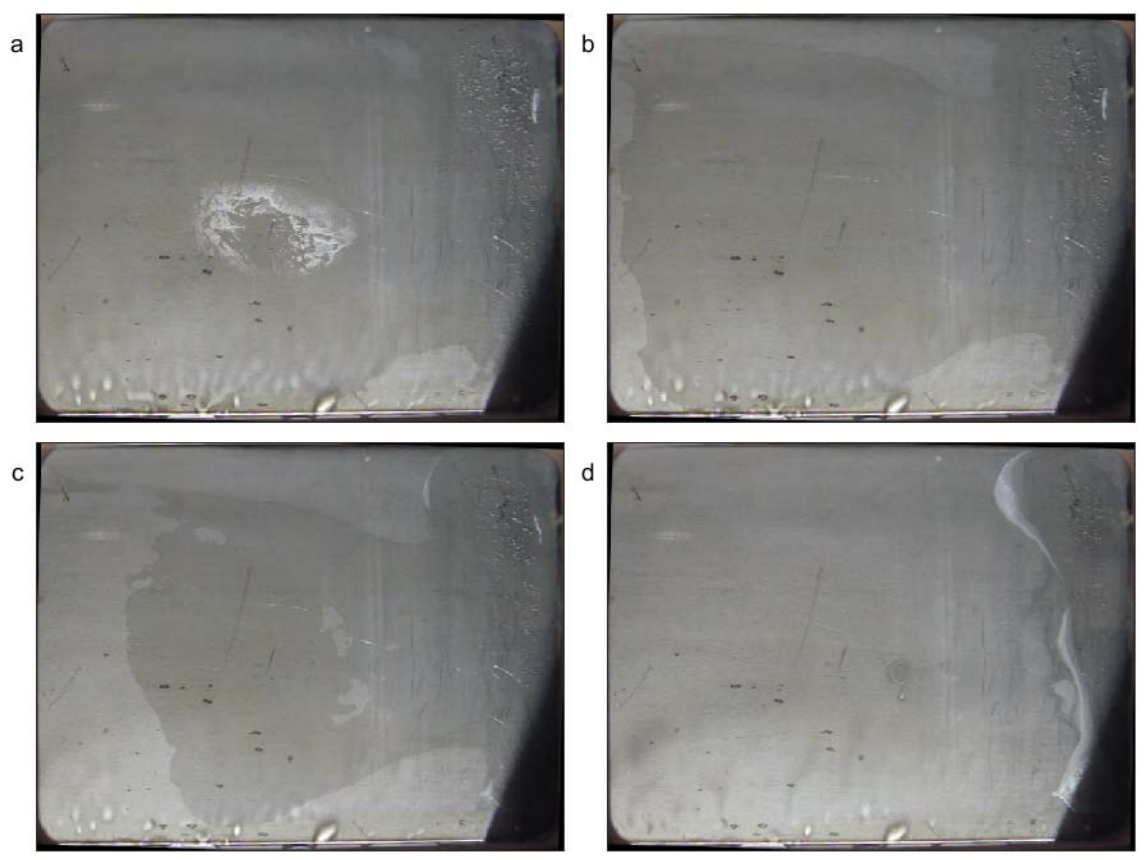

Fig. 16 Urea enriched film starts evaporating from the upstream side, and white deposits form in the downstream side a) $\mathrm{EOI+23s,} \mathrm{b)} \mathrm{EOI+46s,} \mathrm{c)} \mathrm{EOI+69s,} \mathrm{d)} \mathrm{EOI+132s.}$ 

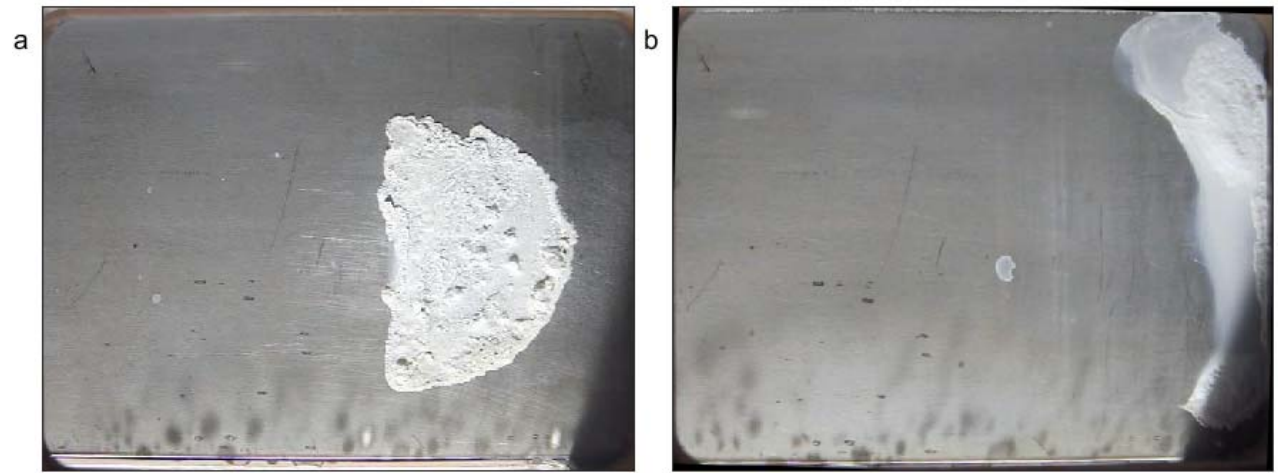

Fig. 17 Deposit location and quantity for different injection durations at the flow condition of $300^{\circ} \mathrm{C} 100 \mathrm{~kg} / \mathrm{h}$ a) $60 \mathrm{~ms}$, b) $120 \mathrm{~ms}$.

\subsection{Solid Deposit Composition Analysis}

Solid deposits removed from the plate (Fig. 17b) have been analyzed by NMR spectroscopy. The main resonance with around $75 \%$ of the total signal intensity is observed at $167.2 \mathrm{ppm}$ and four resonances of minor compounds are detected at 169.1, 168, 166.5 and 164.7 ppm as shown in Fig. 18a. In a series of further experiments, small aliquots of reference materials urea, biuret, triuret, cyanuric acid, ammelide, ammeline or melamine were added to the sample solution. From the increases of individual resonances after spiking with individual resonance compounds, the compounds ammelide, ammeline and biuret were unambiguously identified (Fig. 18b-d). The main resonance at $167.2 \mathrm{ppm}$ in the ${ }^{13} \mathrm{C}$ NMR spectrum is assigned to cyanuric acid (spectrum not shown). Please note that the recording of ${ }^{13} \mathrm{C}$ NMR data of the pristine reference material throughout resulted in considerably different chemical shifts not directly comparable to the signals observable in the spectrum of the sample. In Fig. 19 the ${ }^{13} \mathrm{C}$ NMR spectra of the sample "as is" and after spiking with the reference materials urea, triuret and ammeline are shown. It is clear from these spectra, that none of the three compounds is present in the mixture at significant amounts since none of the additional signals match to the resonances of the sample solution (Fig. 19a). The decomposition of cyanuric acid initiates at $320^{\circ} \mathrm{C}$ and is limited by the reaction kinetics [13]. Therefore, cyanuric acid and the other chemical species remain in the form of permanent deposits for the $300^{\circ} \mathrm{C}$ case. From line shape analysis (see experimental part) and under consideration of the formulae shown in Eq. (2) the composition [wt-wt-\%] of sample was determined as $73.0 \%$ cyanuric acid, $13.8 \%$ biuret, $11.8 \%$ ammelide and $1.5 \%$ ammeline. In Tab. 5 the sample compositions of all data shown in Fig. 18 and Fig. 19 are summarized. It is clearly observable that as expected the spiking with reference material 
is reflected in an increase of the amount of the respective material. It must be mentioned that depending on $\mathrm{pH}$ and sample concentrations we observed a considerable variation of the ${ }^{13} \mathrm{C}$ chemical shifts in $\mathrm{NaOD} / \mathrm{D}_{2} \mathrm{O}$ solutions. It seems that for each sample of interest with an essentially different composition, the above mentioned laborious signal assignment procedure must be carried out.

\begin{tabular}{|l|c|c|c|c|c|c|c|}
\hline compound & ammelide & ammeline & cyanuric acid & biuret & melamine & urea & triuret \\
\hline sample & & & & & & & \\
\hline "as is" & $11.8 \%$ & $1.5 \%$ & $73.0 \%$ & $13.8 \%$ & & & \\
\hline \& urea & $7.6 \%$ & $1.2 \%$ & $48.9 \%$ & $7.9 \%$ & & $34.3 \%$ & \\
\hline \& biuret & $8.7 \%$ & $2.0 \%$ & $58.1 \%$ & $31.2 \%$ & & & \\
\hline \& triuret & $8.3 \%$ & $1.1 \%$ & $50.1 \%$ & $10.0 \%$ & & & $30.4 \%$ \\
\hline \& melamine & $7.2 \%$ & $1.4 \%$ & $51.7 \%$ & $6.2 \%$ & $33.6 \%$ & & \\
\hline \& ammeline & $9.4 \%$ & $26.1 \%$ & $54.6 \%$ & $9.9 \%$ & & & \\
\hline \& ammelide & $21.0 \%$ & $1.8 \%$ & $65.5 \%$ & $11.8 \%$ & & & \\
\hline \& cyanuric acid & $3.7 \%$ & $0.6 \%$ & $90.8 \%$ & $4.9 \%$ & & & \\
\hline
\end{tabular}

Tab. 5 Sample compositions determined by quantitative evaluation of ${ }^{13} \mathrm{C}$ NMR data of sample under the condition of $300{ }^{\circ} \mathrm{C}, 100 \mathrm{~kg} / \mathrm{h} 120 \mathrm{~ms}$ "as is" and after addition of small aliquots of reference material $\left({ }^{13} \mathrm{C}\right.$ NMR spectra shown in Fig. 18 and Fig. 19).

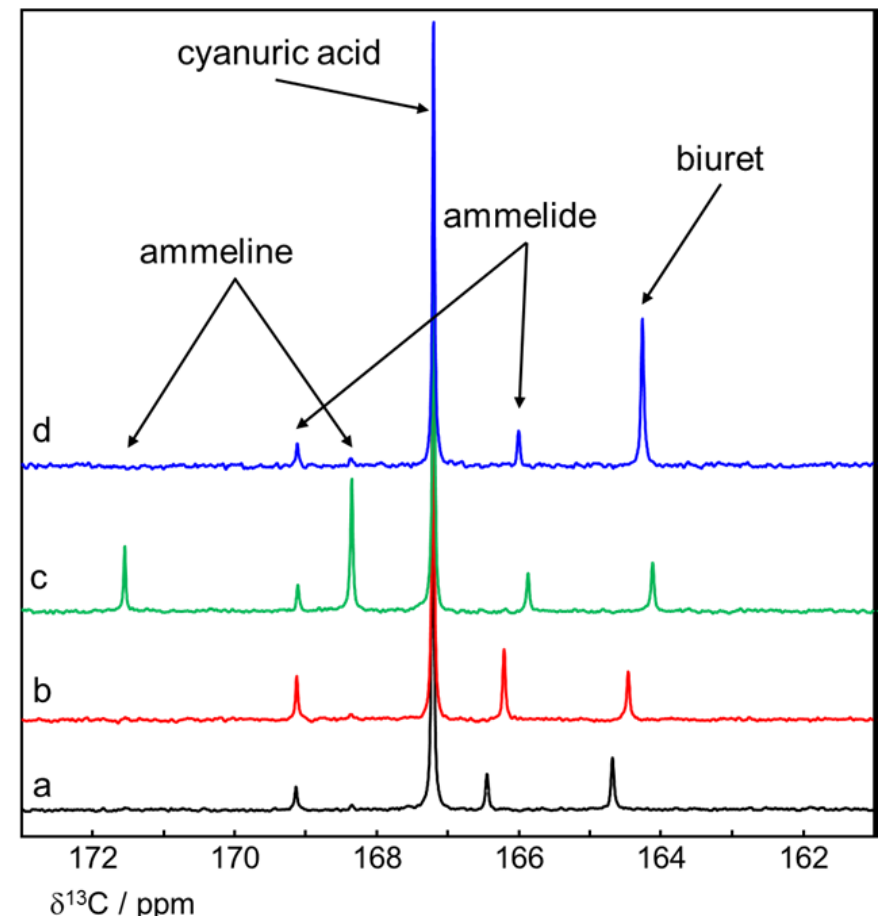

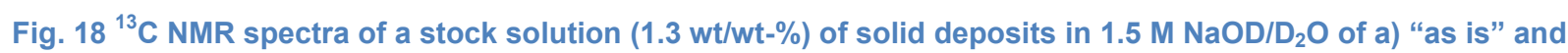
after addition of small quantities of b) ammelide, c) ammeline and d) biuret. 


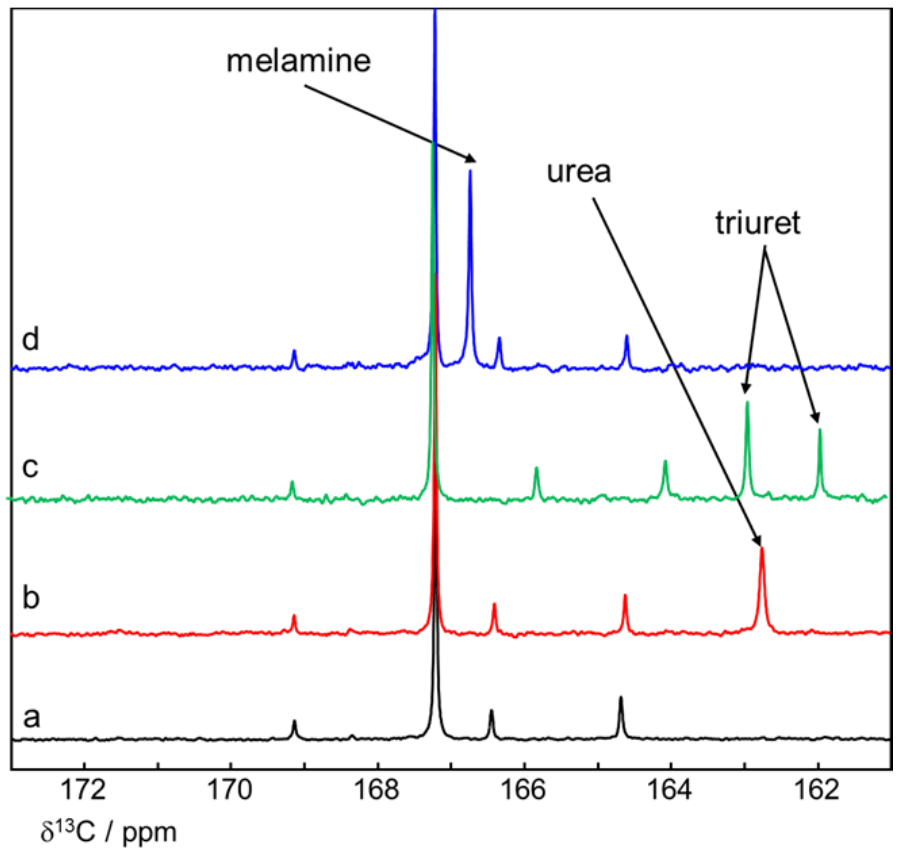

Fig. $19{ }^{13} \mathrm{C}$ NMR spectra of a stock solution (1.3 wt/wt-\%) of solid deposits in $1.5 \mathrm{M} \mathrm{NaOD/D2O}$ of a) "as is" and after addition of small quantities of b) urea, c) triuret and d) melamine.

Under all tested conditions, permanent solid deposits have been observed in the liquid accumulation site. The relatively high decomposition temperature of the main component, cyanuric acid, implies the difficulties to remove it once it is formed. As shown in the previous section, deposit formation always follows liquid film formation, which is directly related to the wall temperature. To avoid the liquid film formation, wall temperatures should always be maintained above the non-wetting threshold $[14,34,45]$. If active heating is needed for maintain the wall temperature, the required power will depend on the spray mass load from Sec. 3.1. According to $[14,29,34]$, the principal spray/wall interaction regimes are rebound and thermal breakup when the wall temperatures exceed the threshold. Breaking up large droplets by thermal breakup would be very advantageous for fast evaporation and uniform mixing with the exhaust gas.

\section{Conclusions}

A detailed experimental investigation of the UWS spray impingement under diesel exhaust typical flow conditions has been performed. First, the spray impinging mass flux and its dependency on the gas flow momentum and temperature have been quantified by a mechanical. Additionally, the impinging droplet size distribution has been characterized by PDA. Furthermore, phenomena associated to the UWS spray 
impingement process, such as liquid film evolution, nucleate boiling and solid deposit formation, have been analyzed through optical high speed imaging experiments. Finally, the solid deposit composition has been identified by NMR spectroscopic analysis. The main conclusions and achievements of this work are:

- Despite the presence of entrainment and evaporation, the spray wall impingement is still significant for such low pressure sprays. Experiments and analysis indicate that finer sprays would reduce the wall impingement.

- The impinging mass is estimated as a function of gas flow temperature and momentum under various exhaust conditions.

- The spray impingement leads to liquid film formation, due to strong local cooling. Thereafter, significant amount of the liquid is transported downstream mainly by the momentum of each injection and forms a liquid accumulation site. Under all tested conditions, permanent solid deposits have been observed in the liquid accumulation site.

- From NMR spectroscopy, it has been determined that the solid deposit is composed of $73.0 \%$ cyanuric acid, $13.8 \%$ biuret, $11.8 \%$ ammelide and $1.5 \%$ ammeline.

Concerning low pressure sprays, wall impingement is unlikely to be avoided by means of varying exhaust flow conditions. Wall impingement leads to liquid film and following formation of solid deposits which are difficult to remove. The observed phenomena and proposed correlations are useful for the design and layout of the injection and mixing sections of the SCR systems. In addition, the experimental results are of paramount importance for calibrating and validating numerical simulations. Maintaining wall temperatures above the non-wetting threshold, which alter the spray/wall interaction regime, would be a promising solution to suppress the deposits. Alternatively, the urea injector could approach the art of fuel injectors, with smaller nozzles and higher operating pressures.

\section{Acknowledgements}

The authors gratefully acknowledge the help of Peter Zolliker from Reliability Science and Technology Laboratory Empa, Bernadette Vogler from Environmental Chemistry Department Eawag, Daniel Schreiber and Thibaut Durand from Automotive Powertrain Technologies Laboratory Empa. The support of Swiss 
Federal Office for the Environment and Robert Bosch $\mathrm{GmbH}$, Germany are highly appreciated. The NMR hardware was partially granted by the Swiss National Science Foundation (SNFS, grant no. 150638).

\section{References}

[1] Koebel M, Elsener M, Kleemann M. Urea-SCR: a promising technique to reduce NOx emissions from automotive diesel engines. Catal Today 2000;59:335-45. doi:10.1016/S0920-5861(00)002996.

[2] Birkhold F, Meingast $U$, Wassermann $P$, Deutschmann O. Modeling and simulation of the injection of urea-water-solution for automotive SCR DeNOx-systems. Appl Catal B Environ 2007;70:119-27. doi:10.1016/j.apcatb.2005.12.035.

[3] Sebelius S, Le TT, Pettersson LJ, Lind H. Identification of urea decomposition from an SCR perspective; A combination of experimental work and molecular modeling. Chem Eng J 2013;231:220-6. doi:10.1016/j.cej.2013.06.124.

[4] Koebel M, Strutz EO. Thermal and Hydrolytic Decomposition of Urea for Automotive Selective Catalytic Reduction Systems : Thermochemical and Practical Aspects. Ind Eng Chem Res 2003;42:2093-100.

[5] Scott Sluder C, Storey JME, Lewis SA, Lewis LA. Low Temperature Urea Decomposition and SCR Performance. SAE Tech Pap 2005-01-1858 2005. doi:10.4271/2005-01-1858.

[6] Mckinley TL, Alleyne AG, Lee C. Mixture Non-Uniformity in SCR Systems: Modeling and Uniformity Index Requirements for Steady- State and Transient Operation 2010;3:486-99.

[7] Xu L, Watkins W, Snow R, Graham G, McCabe R, Lambert C, et al. Laboratory and Engine Study of Urea-Related Deposits in Diesel Urea-SCR After-Treatment Systems. SAE Tech Pap 2007;2007. doi:10.4271/2007-01-1582.

[8] Strots VO, Santhanam S, Adelman BJ, Griffin G a., Derybowski EM. Deposit Formation in UreaSCR Systems. SAE Int J Fuels Lubr 2009;2:283-9. doi:10.4271/2009-01-2780.

[9] Munnannur A, Chiruta M, Liu ZG. Thermal and Fluid Dynamic Considerations in Aftertreatment System Design for SCR Solid Deposit Mitigation. SAE Tech Pap 2012. doi:10.4271/2012-01-1287.

[10] Spiteri A, Dimopoulos Eggenschwiler P, Liao Y, Wigley G, Michalow-Mauke KA, Elsener M, et al. Comparative analysis on the performance of pressure and air-assisted urea injection for selective catalytic reduction of NOx. Fuel 2015;161:269-77. doi:10.1016/j.fuel.2015.08.061.

[11] Schaber PM, Colson J, Higgins S, Thielen D, Anspach B, Brauer J. Thermal decomposition (pyrolysis) of urea in an open reaction vessel. Thermochim Acta 2004;424:131-42. doi:10.1016/j.tca.2004.05.018.

[12] Eichelbaum M, Siemer AB, Farrauto RJ, Castaldi MJ. Applied Catalysis B : Environmental The impact of urea on the performance of metal-exchanged zeolites for the selective catalytic reduction of NO x - Part II . Catalytic , FTIR , and NMR studies. Appl Catal B Environ 2010;97:98-107. doi:10.1016/j.apcatb.2010.03.028.

[13] Bernhard AM, Peitz D, Elsener M, Wokaun A, Kröcher O. Hydrolysis and thermolysis of urea and its decomposition byproducts biuret, cyanuric acid and melamine over anatase TiO2. Appl Catal B Environ 2012;115-116:129-37. doi:10.1016/j.apcatb.2011.12.013.

[14] Birkhold F, Meingast U, Wassermann P. Analysis of the Injection of Urea-Water-Solution for Automotive SCR DeNOx-Systems : Modeling of Two-Phase Flow and Spray / Wall-Interaction. SAE Int 2006;2006-01-06. 
[15] Jeong S-J, Lee S-J, Kim W-S. Numerical study on the optimum injection of urea- water solution for SCR DeNOx system of a heavy-duty diesel engine to improve DeNOx performance and reduce NH3 slip. Environ Eng Sci 2008;25:1017-36. doi:10.1089/ees.2007.0224.

[16] Helden R Van, Verbeek R, Willems F, van der Welle R. Optimization of Urea SCR deNOx Systems for HD Diesel Engines ABSTRACT CATALYST CONFIGURATION AND UREA. SAE 2004 World Congr Exhib 2004;1:13. doi:10.4271/2004-01-0154.

[17] Risi A De, Donateo T, Sciolti A, Calò M, Gaballo MR. A New Energy-based Model for the Prediction of Primary Atomization of Urea-Water Sprays. SAE Int 2009;2009-01-09.

[18] Varna A, Boulouchos K, Spiteri A, Dimopoulos Eggenschwiler P, Wright YM. Numerical Modelling and Experimental Characterization of a Pressure-Assisted Multi-Stream Injector for SCR Exhaust Gas After-Treatment. SAE Int J Engines 2014;7:2012-21. doi:10.4271/2014-01-2822.

[19] Varna A, Spiteri AC, Wright YM, Dimopoulos P. Experimental and numerical assessment of impingement and mixing of urea - water sprays for nitric oxide reduction in diesel exhaust q. Appl Energy 2015;157:824-37. doi:10.1016/j.apenergy.2015.03.015.

[20] Nocivelli L, Montenegro G, Liao Y, Dimopoulos P. Modeling of Aqueous Urea Solution injection with characterization of spray-wall cooling effect and risk of onset of wall wetting. Energy Procedia 2015;82:38-44. doi:10.1016/j.egypro.2015.11.880.

[21] Lundström A, Ström H. Modeling aspects of the injection of urea-spray for NOx abatement for heavy duty diesel engines. Sprays Types, Technol. Model., 2011, p. 257-86.

[22] Hua L, Zhao Y, Hu J, Tao T. Comparison Between Air-Assisted and Airless Urea Spray for Diesel SCR System by PDA and CFD. SAE Tech Pap 2012. doi:10.4271/2012-01-1081.

[23] Spiteri A, Dimopoulos Eggenschwiler P. Experimental fluid dynamic investigation of urea-water sprays for diesel selective catalytic reduction-denox applications. Ind Eng Chem Res 2014;53:3047-55. doi:10.1021/ie404037h.

[24] Grout S, Blaisot JB, Pajot K, Osbat G. Experimental investigation on the injection of an urea-water solution in hot air stream for the SCR application: Evaporation and spray/wall interaction. Fuel 2013;106:166-77. doi:10.1016/j.fuel.2012.09.022.

[25] Oh J, Lee K. Spray characteristics of a urea solution injector and optimal mixer location to improve droplet uniformity and NOx conversion efficiency for selective catalytic reduction. Fuel 2014;119:90-7. doi:10.1016/j.fuel.2013.11.032.

[26] Shi X, Deng J, Wu Z, Li L. Effect of injection parameters on spray characteristics of urea-SCR system. SAE Int J Engines 2013;6:873-81. doi:10.4271/2013-01-1067.

[27] Muzard A. Development of a 3D spray visualisation method for low-pressure injectors. MTZ 2013:50-5.

[28] Liao Y, Dimopoulos Eggenschwiler P, Spiteri A, Nocivelli L, Montenegro G, Boulouchos K. Fluid Dynamic Comparison of AdBlue Injectors for SCR Applications. SAE Int J Engines 2015;8:201524-2502. doi:10.4271/2015-24-2502.

[29] Liao Y, Furrer R, Dimopoulos P, Boulouchos K. Experimental investigation of the heat transfer characteristics of spray / wall interaction in diesel selective catalytic reduction systems. Fuel 2017;190:163-73. doi:10.1016/j.fuel.2016.11.035.

[30] Brack W, Heine B, Birkhold F, Kruse M, Deutschmann O. Formation of Urea-Based Deposits in an Exhaust System : Numerical Predictions and Experimental Observations on a Hot Gas Test Bench. Emiss Control Sci Technol 2016:115-23. doi:10.1007/s40825-016-0042-2. 
[31] Smith H, Lauer T, Mayer M, Pierson S. Optical and Numerical Investigations on the Mechanisms of Deposit Formation in SCR Systems. SAE Tech Pap 2014. doi:10.4271/2014-01-1563.

[32] Musa S, Saito M, Furuhata T, Arai M. Evaporation characteristics of a single aqueous urea solution droplet. ICLASS-2006, Kyoto, Pap ID ICLASS06- 195 2006;2.

[33] Wang TJ, Baek SW, Lee SY, Kang DH, Yeo GK. Experimental investigation on evaporation of urea-water-solution droplet for SCR applications. AIChE J 2009;55:3267-76. doi:10.1002/aic.

[34] Kuhnke D. Spray Wall Interaction Modelling by Dimensionless Data Analysis. PhD thesis. Universität Darmstadt, 2004.

[35] Moreira ALN, Moita AS, Panão MR. Advances and challenges in explaining fuel spray impingement: How much of single droplet impact research is useful? Prog Energy Combust Sci 2010;36:554-80. doi:10.1016/j.pecs.2010.01.002.

[36] Wang Z, Ding H, Ma X, Xu H, Wyszynski ML. Ultra-high speed imaging study of the diesel spray close to the injector tip at the initial opening stage with single injection. Appl Energy 2016;165:33544. doi:10.1016/j.apenergy.2015.12.046.

[37] Wang Z, Li Y, Wang C, Xu H, Wyszynski ML. Experimental study on primary breakup of diesel spray under cold start conditions. Fuel 2016;183:617-26. doi:10.1016/j.fuel.2016.06.067.

[38] Puschmann F, Specht E. Transient measurement of heat transfer in metal quenching with atomized sprays. Exp Therm Fluid Sci 2004;28:607-15. doi:10.1016/j.expthermflusci.2003.09.004.

[39] Li BQ, Cader T, Schwarzkopf J, Okamoto K, Ramaprian B. Spray angle effect during spray cooling of microelectronics: Experimental measurements and comparison with inverse calculations. Appl Therm Eng 2006;26:1788-95. doi:10.1016/j.applthermaleng.2006.01.023.

[40] Gradeck M, Ouattara JA, Rémy B, Maillet D. Solution of an inverse problem in the Hankel space Infrared thermography applied to estimation of a transient cooling flux. Exp Therm Fluid Sci 2012;36:56-64. doi:10.1016/j.expthermflusci.2011.08.003.

[41] Labergue A, Gradeck M, Lemoine F. Comparative study of the cooling of a hot temperature surface using sprays and liquid jets. Int J Heat Mass Transf 2015;81:889-900. doi:10.1016/j.jijheatmasstransfer.2014.11.018.

[42] Al-Ahmadi HM, Yao SC. Spray Cooling of High Temperature Metals Using High Mass Flux Industrial Nozzles. Exp Heat Transf 2008;21:38-54. doi:10.1080/08916150701647827.

[43] Bernhard AM. Catalytic urea decomposition, side-reactions and urea evaporation in the selective catalytic reduction of NOx. PhD Thesis 2012;1.

[44] Massiot D, Fayon F, Capron M, King I, Calv L, Alonso B, et al. Modelling one- and two-dimensional solid-state NMR spectra. Magn Reson Chem 2002;40:70-6. doi:10.1002/mrc.984.

[45] Liao Y, Nocivelli L, Eggenschwiler PD, Spiteri A. Experimental investigation of heat transfer characteristics of urea spray impingement in diesel SCR. Proc 15 Int Stuttgarter Symp 2015:1-15. 